\title{
O PAPEL ASSISTENCIALISTA DO BRASIL PARA COM OS REFUGIADOS À LUZ DA DIMENSÃO HOLÍSTICA DA SAÚDE
}

\author{
THE EXISTENTIALIST ROLE OF BRAZIL TO REFUGEES IN THE \\ LIGHT OF THE HOLISTIC DIMENSION OF HEALTH
}

Rosimeire Cristina Andreotti ${ }^{1}$

RESUMO: Este artigo objetiva tratar do papel assistencialista do Brasil para com os refugiados à luz da dimensão holística da saúde. Trata-se de um estudo que pretende explanar, mesmo que em breves palavras, acerca do arcabouço legislativo que envolve o instituto humanitário do refúgio, tanto no cenário internacional quanto interno. Para tanto, faz-se necessário um resgate histórico de diplomas legais que impactaram na questão do refúgio, tanto no cenário internacional, quanto nacional, tais como a Declaração Universal dos Direitos Humanos, de 1948, passando pela Convenção de 1951, o Protocolo de 1967, a Lei ${ }^{\circ} 9.474 / 1997$ e finalmente a Lei $n^{\circ}$ 13.445/2017. Na sequência, o direito à saúde ganha destaque, como forma de explicitar qual a amplitude desse direito fundamental no Brasil, considerando que ser saudável envolve bem-estar físico, mental e social. E, por fim, o realce passa à análise das necessidades assistenciais da população que busca por refúgio em território pátrio, frente ao que efetivamente tem sido implementado no país. Metodologicamente, trata-se de uma pesquisa de natureza básica, exploratória e cuja abordagem será a qualitativa. Ademais, o procedimento técnico será o bibliográfico, com a exploração do assunto, por meio de leituras de livros, revistas e sites oficiais que de forma oportuna tratam do tema em foco. Além disso, enquanto a dedução será utilizada como método apropriado de abordagem, o comparativo será - método de procedimento. O Brasil, ao se comprometer tanto no cenário internacional quanto internamente, a receber refugiados, garante a eles o gozo de direitos e garantias fundamentais, dentre os quais está o direito à saúde. Dessa forma, o refugiado em território nacional, pode e deve receber todo atendimento que necessitar, de modo que, considerando a amplitude do conceito de saúde, que envolve o bem-estar físico, mental e social, assim deverá ser o assistencialismo do Estado, que não poderá limitar-se às mazelas físicas dessa população, mas deverá

\footnotetext{
${ }^{1}$ Advogada (OAB/MT sob n.24038); Especialista em Docência no Ensino Superior (lato sensu) pela Faculdade de Ciências Jurídicas e Sociais Aplicadas do Araguaia, e pós-graduanda em Direito Civil e Processo Civil (lato sensu) pelo Centro Universitário UniCathedral. Possui Bacharelado em Direito pela Faculdade de Ciências Jurídicas e Sociais Aplicadas do Araguaia (2012) e Licenciatura Plena em Letras - Português e Literaturas - pela Universidade Federal de Mato Grosso (2006). Integra o Corpo Docente no Curso de Direito do Centro Universitário UniCathedral.
} 
estar atento, também, às psicológicas. A esse respeito, iniciativas felizes vêm sendo implementadas no Rio de Janeiro e em Roraima, contudo, dadas as necessidades da atualidade, revelam-se ainda insuficientes para atender um contingente populacional que cresce cada dia mais.

PALAVRAS CHAVE: Refugiados, Direito à Saúde. Dimensão Holística, Assistencialismo Estatal.

ABSTRACT: This article aims to address Brazil's assistance role for refugees in the light of the holistic dimension of health. It is a study that intends to explain, even in brief words, about the legislative framework that involves the humanitarian institute of refuge, both in the international and domestic scenario. To this end, it is necessary to retrieve historic diplomas that impacted the issue of refuge, both on the international and national scene, such as the 1948 Universal Declaration of Human Rights, passing through the 1951 Convention, the 1967 Protocol, Law No. 9,474 / 1997 and finally Law No. 13,445 / 2017. Then, the right to health is highlighted, as a way of explaining the breadth of this fundamental right in Brazil, considering that being healthy involves physical, mental and social well-being. And, finally, the emphasis goes to the analysis of the assistance needs of the population that seeks refuge in the homeland, in face of what has actually been implemented in the country. Methodologically, it is a basic research, exploratory with a qualitative approach. In addition, the technical procedure will be bibliographic, with the exploration of the subject, through readings of books, magazines and official websites that in a timely manner deal with the subject in focus. Moreover, the deduction will be used as a method of approach, and the method of procedure will be comparative. Brazil, by committing itself both internationally and internally, to receiving refugees, guarantees them the enjoyment of fundamental rights and guarantees, among which is the right to health. In this way, the refugee in the national territory can and must receive all the assistance he needs, so that, considering the breadth of the concept of health, which involves physical, mental and social well-being, so should the welfare of the State, that he cannot limit himself to the physical problems of that population, but he must also pay attention to psychological ones. In this regard, happy initiatives are being implemented in Rio de Janeiro and Roraima, however, given the needs of today, they are still insufficient to meet a population contingent that grows more and more.

KEYWORDS: Refugees, Right to Health. Holistic Dimension, State Assistance. 


\section{INTRODUÇÃO}

Etimologicamente derivada do latim refugium, a palavra refúgio designa o "lugar que alguém procura para fugir ou para se livrar de um perigo; abrigo" (DIClO, 2020 , p. 1). Entretanto, mais do que uma opção, o refúgio enquanto instituto internacional de natureza humanitária caracteriza-se como uma proteção internacional concedida àquele que temendo por sua vida ou integridade física, por pertencer a determinado grupo social, possuir certa opinião política, ou simplesmente por sua raça, nacionalidade ou religião, fez da migração uma necessidade e não uma escolha. Isso porque, ao sair de seu país para proteger sua vida e dignidade, o refugiado se torna vulnerável, e por isso merecedor da proteção internacional.

De acordo com dados apresentados pelo Alto Comissariado das Nações Unidas para Refugiados (ACNUR), até junho de 2019, cerca de "mais de 70,8 milhões de pessoas em todo o mundo foram forçadas a deixar suas casas. Entre elas estão 25,9 milhões de refugiados, [...]". (ACNUR, 2019, p. 01).

O Brasil, em meio a esse gigantesco deslocamento de pessoas que ocorre no planeta, inegavelmente acompanha a tendência mundial de receber cada vez mais migrantes, e dentre esses, os que buscam pelo refúgio. Tanto é dessa maneira que "o Brasil já reconheceu mais de 10 mil refugiados" até maio de 2019 (MINISTÉRIO DA JUSTIÇA E SEGURANÇA PÚBLICA, 2020, p. 1). Trata-se de um número pouco significativo, se comparado à tendência mundial, mas a realidade sinaliza para um algarismo expressivamente maior se considerar todos aqueles que buscaram pelo refúgio e não conseguiram, ou mesmo, os que de fato são refugiados, mas não buscaram o reconhecimento dessa condição pelas autoridades brasileiras.

Segundo aponta Martins-Borges (2013, p. 151-152), o que motiva a migração são os conflitos armados ou mesmo as catástrofes naturais. Entretanto, independentemente do motivo, invariavelmente, esses deslocamentos populacionais estão envoltos em muito sofrimento. Isso porque, graças às situações de extrema 
violência que ocasionam o refúgio, tais como perseguições, torturas e guerras, as pessoas expostas a tais condições acabam padecendo tanto de traumas físicos, dada as condições da viagem, quanto psicológicos, dado os sentimentos de fracasso pelas perdas sofridas, ou mesmo nostalgia, pela vida que possuíam, o que resulta em uma população que, potencialmente, possui problemas de saúde física e mental.

Diante de tal constatação, esta pesquisa se constrói entorno do Direito à Saúde dos Refugiados no Brasil, como forma de desvendar qual deve ser o papel do Estado na assistência à saúde daqueles que buscam pelo refúgio em território nacional, considerando a dimensão holística desse direito.

Trata-se de um estudo, cujo objetivo fundamental visa analisar qual a extensão do Direito à Saúde enaltecido na Constituição Federal, considerando todas as fragilidades que vitimam os refugiados. Isso porque, os refugiados correspondem a um público que, potencialmente, padece de patologias físicas e psicológicas, provocadas pela migração forçada que sofreram, pelas condições da viagem, pelo trauma de serem despojados de seus bens e de tudo que, até então, os ligavam à vida que tinham, pela perda de parentes, que não puderam acompanhar ou estão mortos. Todos esses fatores justificam a investigação que pretende desvendar qual a postura legal assumida pelo Brasil, com relação aos refugiados e à migração, no que tange a saúde dessa população.

Metodologicamente, a investigação ora proposta, revela-se como uma pesquisa de natureza básica, cuja finalidade é a geração de novos conhecimentos para solução de problemas universais. Para isso, a forma de abordagem será a qualitativa, já que, muito mais do que demonstrar dados numéricos, pretende-se analisar a extensão da assistência a ser dispensada pelo Estado brasileiro aos refugiados, tendo em vista o conceito de saúde, e por consequência o acesso a esse direito. Desta forma, outro não poderia ser o objetivo, senão o que revela uma pesquisa exploratória, já que visa promover uma aproximação do problema envolvendo a questão do direito à saúde dos refugiados no Brasil.

Ademais, o procedimento técnico será o que corresponde à pesquisa bibliográfica, cujo alicerce investigatório se dará com base em livros, artigos e sites oficiais dedicados ao tema ora em voga. Além disso, enquanto a dedução será 
utilizada como método apropriado de abordagem, o comparativo será o método de procedimento. Este pela necessidade de investigar e explicar as questões relacionadas à saúde da população refugiada no Brasil, e aquele pelo fato de que, primeiramente, será eleita a legislação, que de forma geral, se dedicada ao refúgio e depois ao direito à saúde, para em seguida, partir para as questões que particularizam a pesquisa ora empenhada, que é analisar a extensão dos deveres prestacionais do Estado brasileiro no tocante à saúde dos refugiados que estão em território nacional.

Calha destacar que, dentre as fontes bibliográficas utilizadas, como autores fundamentais, merece especial ênfase, Martins-Borges (2013), Mazzuoli (2018), Oliveira (2016), Piovesan (2018), dada inquestionável autoridade que possuem sobre o assunto ora tratado.

Além disso, este artigo apresentará, inicialmente e em breves palavras, a trajetória histórica do direito dos refugiados, para com isso, delinear a estrutura jurídica dedicada a esse público, tanto internacional quanto internamente. $\mathrm{Na}$ sequência, o direito à saúde será objeto de análise, verificando-o, desde seu reconhecimento como direito humano, até a constatação de sua dimensão holística, ou seja, a saúde considerada de forma integral. E por fim, o assunto em pauta será o assistencialismo do Estado brasileiro frente à saúde dos refugiados, questão que traz a problematização fundamental desse estudo.

Resta salientar, enfim, que a investigação ora desvelada tem o firme propósito de servir ao enriquecimento do repositório científico acerca da matéria.

\section{TRAJETÓRIA HISTÓRICA DO DIREITO DOS REFUGIADOS}

Apesar da efervescência do tema na atualidade, o fenômeno migratório é tão antigo quanto são os deslocamentos humanos em busca de sobrevivência. Todavia, segundo Ramos (2016, p. 88), foi o deslocamento da população russa, que fugia da Revolução de 1917, que fez surgir, em 1921, um Alto Comissariado para Refugiados. Tratava-se de um órgão, cuja criação foi autorizada pelo Conselho das 
Nações Unidas, mas que originalmente surgiu para dar apoio humanitário a determinados grupos, tais como russos e armênios.

A questão do refúgio passou a ganhar maior abrangência somente após a Segunda Guerra Mundial, quando milhares de europeus deixaram seus países fugindo dos horrores do conflito. Além disso, também contribuiu para a indiscutível valorização do tema, a menção feita pela Declaração Universal dos Direitos Humanos, de 1948, que declara em seu art. XIV que "Todo ser humano, vítima de perseguição, tem o direito de procurar e de gozar asilo em outros países." (DUDH, 1948, p. 1).

Indiscutivelmente, a migração, nesse momento, ganha status de Direito Humano, e como tal, "[...] é gênero, do qual o direito ao refúgio é espécie". (PINHEIRO, 2017, p. 221). Reconhecida assim, passa gozar da dignidade aferida pela lei, e, mesmo que seja um reconhecimento mais formal que material, como salienta Pinheiro (2017, p. 226), o fato é que, como efeito dessa conscientização, em 1950, o Alto Comissariado das Nações Unidas para Refugiados (ACNUR), é criado. Como agência da ONU para refugiados, esse órgão teve seu funcionamento regido pela Convenção relativa ao Estatuto dos Refugiados, também conhecida como Convenção de 1951.

Mas, tal como bem esclarece Mazzuoli (2018, p. 384), a Convenção de 1951, da forma como foi originalmente concebida, estava longe de corresponder ao ideal humanístico esperado. Isso porque possuía uma limitação temporal e geográfica que somente foi superada com o Protocolo de 1967, quando o acolhimento humanitário deixou de estar limitado aos acontecimentos ocorridos antes de $1^{\circ}$ de janeiro de 1951 ou somente voltados à situação dos Refugiados na Europa.

Dessa forma, a partir de 1967, qualquer pessoa que se enquadrasse na descrição prevista, seria considerada refugiada, e, portanto, digna de proteção internacional. Assim, o Alto Comissariado das Nações Unidas para Refugiados (ACNUR), define que refugiados.

São pessoas que estão fora de seu país de origem devido a fundados temores de perseguição relacionados a questões de raça, religião, nacionalidade, pertencimento a um determinado grupo social ou opinião política, como também devido à grave e generalizada violação de direitos humanos e conflitos armados. 
(UNHCR ACNUR AGÊNCIA DA ONU PARA REFUGIADOS, 2020, p. 1).

Tanto a Convenção de 1951, quanto o Protocolo de 1967 foram ratificados pelo Brasil, a convenção em 1961 e o protocolo em 1972. Mas, a benevolência nacional em favor dos refugiados foi realmente demonstrada em 1997, com a promulgação da Lei No 9.474, conhecida como "Estatuto dos Refugiados", que definia os mecanismos para a implementação do Estatuto dos Refugiados de 1951.

A esse respeito, com muita propriedade Mazzuoli (2018, p. 387) destaca que, além do tema do refúgio ter sido abordado com magnífica amplitude, a referida lei brasileira também foi pioneira em implementar um tratado de direitos humanos em território nacional. Neste contexto, fica claro que a Lei № 9.474/97 possui inestimável importância no catálogo normativo brasileiro, uma vez que denuncia a propensão do Brasil em entrar em sintonia com documentos internacionais, que defendem o tema. Além disso, igualmente, foi por obra dessa lei que o Brasil criou também o Comitê Nacional para os Refugiados - CONARE, órgão responsável para tratar internamente do assunto.

Mas, a predisposição brasileira às questões humanitárias, em especial ao acolhimento, foi confirmada, de fato, com a promulgação, em 2017, da Lei $N^{\circ}$ 13.445, conhecida como a nova Lei de Migração. Responsável pela revogação total do "Estatuto do Estrangeiro", Lei № 6.815/1980, a Lei de Migração ao entrar em vigor, definitivamente, consagrou o Brasil como uma pátria acolhedora. Isso porque, dentre os princípios e diretrizes, presentes no art. $3^{\circ}$, estabeleceu "II - repúdio e prevenção à xenofobia, ao racismo e a quaisquer formas de discriminação; III - não criminalização da migração; [...] VI - acolhida humanitária;" (BRASIL, 2017, p. 1).

Sem dúvida, a nova estrutura principiológica a reger a migração no país fortaleceu a humanidade dispensada ao tema, e consequentemente beneficiou aqueles que, em território brasileiro, já eram ou pretendiam ser beneficiados pelo refúgio.

Além disso, no art. $4^{\circ}$ da Lei de Migração, responsável por igualar as condições dos migrantes aos dos nacionais, dentre as garantias oferecidas, destacou na redação do inciso VIII o "acesso a serviços públicos de saúde [...] sem 
discriminação em razão da nacionalidade e da condição migratória;" (BRASIL, 2017, p. 1), o que, definitivamente, inclui o refugiado.

Nesse passo, convém na sequência, tratar do direito à saúde no Brasil, de modo a abordar sua abrangência e consequente responsabilidade do Estado.

\section{O DIREITO À SAÚDE}

Notadamente, se foi por obra da Declaração Universal dos Direitos Humanos, de 1948, que a migração, e por consequência o refúgio, alçaram ao status de Direito Humano, e a saúde também foi. Isso pode ser comprovado nas letras do art. XXV que assevera que "Todo ser humano tem direito a um padrão de vida capaz de assegurar-lhe, e a sua família, saúde e bem-estar, [...] cuidados médicos e os serviços sociais indispensáveis [...]". (DUDH, 1948, p. 1).

No mesmo sentido, o Pacto Internacional de Direitos Econômicos, Sociais e Culturais, de 1966, em seu art. 12, expressou a importância do Direito Humano à Saúde ao declarar que "Os Estados-partes no Presente Pacto reconhecem o direito de toda pessoa de desfrutar o mais elevado nível de saúde física e mental". No mesmo sentido, em 1969, a Convenção Americana sobre Direitos Humanos, também estabeleceu em seu art. $5^{\circ}$ que "Toda pessoa tem direito a que se respeite sua integridade física, psíquica e moral".

Desta forma, o Direito à Saúde, já consagrado como Direito Humano, dada sua presenta nos documentos internacionais mencionados, em 1988 também estava presente no acervo de Direitos e Garantias Fundamentais, ao incrementar os Direitos Sociais presentes na Constituição Federal.

Entretanto, o devido destaque ao tema somente ocorreu na redação do art. 196 da Lei Maior, quando o legislador constitucional pontuou a saúde como "direito de todos e dever do Estado, garantido mediante políticas sociais e econômicas que visem à redução do risco de doença e de outros agravos e ao acesso universal igualitário às ações e serviços para sua promoção, proteção e recuperação [...]" (BRASIL, 1988, p. 1). 
Notadamente, a Carta Magna democratizou o direito à saúde, ao defini-la como "direito de todos" e propondo um "acesso universal igualitário". No entanto, o ordenamento pátrio somente adequou à completude do termo saúde, por obra da Lei $N^{\circ}$ 8.080/1990, que, no parágrafo único do art. $3^{\circ}$, expressa como fatores relacionados à saúde as "[...] condições de bem-estar físico, mental e social" (BRASIL, 1990, p. 1). Nesse momento, a saúde passava a ser considerada em sua dimensão holística, colocando o arcabouço legislativo brasileiro em franca sintonia com a concepção de saúde presente em organismos internacionais, como a Organização Pan-Americana da Saúde/Organização Mundial da Saúde (OMS), para a qual ser saudável corresponde ao "[...] bem-estar físico, mental e social de uma pessoa", e não apenas a simples ausência de doenças (OPAS/OMS BRASIL, 2020, p. 1).

Assim, tal como foi prevista no art. 12 da Declaração Universal dos Direitos Humanos, e expandida pela Organização Pan-Americana da Saúde/Organização Mundial da Saúde (OMS), ser saudável é gozar de bem-estar físico, mental e social. Por isso, o direito à saúde, da forma como foi tecido no ordenamento jurídico pátrio, corresponde não apenas a ausência de doença, mas abarca um complexo de outros fatores que contribuem para o bem-estar do indivíduo, tais como alimentação, moradia, saneamento básico, trabalho, renda, educação, transporte, lazer, meio ambiente etc.

O desequilíbrio ou mesmo a completa ausência desses fatores, que guardariam relação com o mínimo existencial relacionado à saúde, seriam os responsáveis por danos não somente à saúde física dos indivíduos, mas também a mental. Essa é a constatação da Organização Pan-Americana da Saúde/Organização Mundial da Saúde (OMS), ao asseverar que "[...] diversos fatores podem colocar em risco a saúde mental dos indivíduos; entre eles, rápidas mudanças sociais, condições de trabalho estressantes, discriminação de gênero, exclusão social, estilo de vida não saudável, violência e violação dos direitos humanos". (OPAS/OMS BRASIL, 2020, p. 1).

Tal constatação torna clara a real extensão da responsabilidade do Estado brasileiro no tocante a garantia do direito a saúde, visto que, de forma interrelacionada, todos os demais direitos sociais previstos no caput do art. $6^{\circ}$ do texto 
constitucional, tais como, a alimentação, o trabalho, moradia, educação, transporte, lazer, segurança, dentre outros, revelam-se mutuamente dependentes e responsáveis pela boa saúde, já que correspondem ao bem-estar, quando não físico, mental ou social do indivíduo.

Considerando tudo que é necessário para que se tenha um ambiente saudável, e a consequente responsabilidade do Estado frente a isso, indispensável se faz, agora, tratar das condições do refugiado, tendo em vista que esse é um público que, cada vez mais chega ao território nacional.

\section{ASSISTENCIALISMO DO ESTADO FRENTE À SAÚDE DOS REFUGIADOS}

Apesar da Lei $N^{\circ}$ 9.474/97 ter feito uma única menção à saúde, oportunamente ao tratar da composição do CONARE, que possui, dentre seus membros, um representante do Ministério da Saúde, o refugiado não ficou legalmente desamparado com relação ao seu direito à saúde no Brasil. Isso porque, tanto a Constituição Federal quanto a Lei de Migração, tal como já foi explanado muito bem, esclarecem quem estão sob a égide do Direito à Saúde no país, que abrange nacionais, estrangeiros e apátridas, universo que muito bem enquadra os refugiados.

Nesse sentido, temos que a questão do assistencialismo em saúde dada pelo Estado brasileiro, conforme bem esclarece a Cartilha para Refugiados no Brasil (2018, p. 23), está voltada fortemente para o bem-estar físico do refugiado, tendo em vista que alerta para a necessidade de vacinação, em especial das crianças, além de esclarecer as possibilidades de atendimento gratuito em qualquer unidade pública de saúde. Essa inserção, notadamente, compromete o Estado brasileiro a atender a essa população em todas as suas necessidades, indo desde vacinação, atendimento hospitalar, internação, dentre outros cuidados, tais como acompanhamento psicológico.

Contudo, é bem verdade que, tal como afirma Borges (2012, p. 578), a noção de saúde esteve, durante muito tempo, voltada para a ausência de doença física, ou 
seja, um bem-estar corporal. Assim, não possuir a necessidade de permanecer em uma instituição hospitalar, para ali receber tratamentos, definia o conceito de saúde.

De acordo com esse raciocínio, fica evidente que o tratamento de saúde global da pessoa, estava prejudicado, haja vista que, tal como já foi dito, o bom estado de saúde revela-se como um complexo de condições que vão muito além da questão de bem-estar corporal do indivíduo, perpassando por sua condição física, mental e social.

Em consonância com esse raciocínio estão as palavras de Ricardo Filipe Rodrigues de Oliveira, segundo as quais

[...] o direito à saúde é um poliedro complexo que abarca diferentes dimensões e que exige o contributo verdadeiramente holístico de factores paralelos como a educação, o emprego, a segurança social e a habitação para que se alcance um estado de bem-estar e conforto de cada indivíduo, visto que saúde não significa a mera ausência de doença. (OLIVEIRA, 2016, p. 4).

Dessa forma, o fato de uma população que busca pelo refúgio em território nacional, não necessitar de tratamento ambulatorial ou mesmo internação hospitalar, de forma alguma garante que esteja integralmente saudável. Pelo contrário, se essas pessoas não sofrem de patologias físicas apesar das condições da viagem, da falta de higiene ou precariedade na alimentação, grandes chances há de sofrerem patologias mentais.

Corrobora com esse raciocínio a lição de Martins-Borges (2013, p. 151), que oportunamente esclarece que o refugiado sofre grande abalo psicológico, dadas as circunstâncias caracterizadoras da vida no exílio. Isso porque, ele é forçado a recomeçar sua vida em um país estranho, muitas vezes sozinho ou sem todos os membros da família, sem conhecer a língua e impossibilitado de comprovar suas habilidades. Toda essa ausência de referencias cultural gera, nos que buscam pelo refúgio, um severo trauma psicológico, já que tiveram que deixar para traz a vida que tinham, e tudo que possuíam sem que tivessem planejado, ou tampouco, desejado.

Também Piovesan (2018, p. 294) alerta acerca das consequências de se necessitar de refúgio, haja vista que há uma marca de temores, abusos e grandes sofrimentos na história de vida de cada homem, mulher e criança que vive o exílio em busca de abrigo e proteção em outro país. Isso porque, ao serem submetidos a 
uma migração forçada, após serem despojados de todos os seus bens, e separados de seus parentes, chegam a terras estranhas, locais que ao menos sabiam que existiam, e do qual ignoram a cultura, a língua, e tudo que era responsável por dar a eles a sensação de pertencimento.

Nesse passo, de acordo com Valdes (2016, p. 68), apesar do direito à saúde no Brasil, apresentar uma proposta de universalidade, que inclui todo aquele que dele necessitar, é indispensável que esse acesso à saúde seja propiciado por meio do devido preparo dos profissionais de atendimento. Isso porque, essa nova demanda de pessoas a necessitar do acesso à saúde no Brasil, enfrenta a barreira da língua, da cultura, de questões religiosas, sociais ou mesmo do preconceito, que apesar de expressamente condenado pela Lei de Migração, definitivamente, ainda está presente quando a questão é migração e refúgio.

Ademais, muito mais do que prezar apenas pelo bem-estar físico dos refugiados que estão em território nacional, o Estado, que já se obrigou a garantir o direito à saúde, precisa, também, oferecer acompanhamento psicológico para essas pessoas.

Acerca dessas questões relacionadas ao direito à saúde do refugiado, Miles e Carlet (2006, p. 1), destaca que, presente no Hospital de Servidores do Estado do Rio de Janeiro, está o Centro de Referência para a Saúde dos Refugiados. Trata-se de uma iniciativa que objetiva desenvolver, nos profissionais do Sistema Único de Saúde (SUS), habilidades que Ihes permitam lidar com as particularidades que envolvem o atendimento ao refugiado em território nacional. Isso indica que atendentes, enfermeiros e médicos devem estar preparados para lidar com dificuldades com a língua, problemas psicológicos decorrentes da degenerada violência que, homens, mulheres e crianças que buscam pelo refúgio, sofreram, e que os fazem merecedores de um atendimento diferenciado.

Entretanto, ainda de acordo com as palavras de Miles e Carlet (2006, p. 1), existem as lacunas na acolhida e efetiva integração dos refugiados em território nacional, e que em matéria de saúde poderiam ser sanadas com as seguintes providências:

1 - Garantir atendimento global à saúde dos refugiados nos serviços de saúde pública, inclusive de saúde psico-social; 2 - 
Elaborar um Programa de Saúde para atendimento à população refugiada e identificação de hospitais de referência; 3 - Criar junto às universidades públicas a possibilidade de atendimento odontológico; 4 - Intervir na formalização de acordos junto às Secretarias de Saúde (Estadual e/ou Municipal) para políticas de saúde de atendimento local aos refugiados. (MILES; CARLET, 2006, p. 1).

Também em sintonia com esta questão, tal como informa Nações Unidas Brasil (2019, p. 1), a Organização Pan-Americana da Saúde/Organização Mundial da Saúde (OPAS/OMS) em parceria com o Alto Comissariado das Nações Unidas para Refugiados (ACNUR), a Organização Internacional de Migração (OIM) e o Fundo das Nações Unidas para a Infância (UNICEF), vem desenvolvendo, desde dezembro de 2019, um projeto intitulado "Fortalecimento de Capacidades Locais em Saúde Mental e Apoio Psicossocial no Contexto do Fluxo Migratório em Boa Vista, Roraima", que objetiva capacitar profissionais de saúde para dar apoio psicossocial aos refugiados, e para tanto, pretende tratar de temas como o manejo clínico dos transtornos mentais, autocuidado, cuidado colaborativo, luto, depressão e suicídio.

Essas referências demonstram que, em território nacional, providências vêm sendo tomadas, na tentativa de bem acolher essa demanda populacional que, cada dia mais, incrementa a população brasileira.

\section{CONSIDERAÇÕES FINAIS}

Notadamente, milhões de pessoas estão em deslocamento pelo mundo na atualidade, e o Brasil acompanha a tendência mundial de receber cada vez mais essas pessoas, que num percentual considerável, são vítimas de uma migração forçada.

Trata-se de uma triste realidade em que homens, mulheres e crianças, que temem por suas vidas ou integridade física, são forçados a deixar suas casas e seus bens, e buscar auxílio e proteção em outros países. São, por isso, chamados pela Sociedade Internacional de refugiados. Reconhecidos em sua vulnerabilidade, são destinatários de proteção internacional, e, considerando a postura brasileira frente a 
temas humanitários, também nacionais. Bem estruturada, num forte arcabouço legislativo, a proteção nacional dispensada ao migrante, e por consequência ao refugiado, perpassa pela Constituição Federal, Estatuto dos Refugiados e Lei de Migração, que seguindo a tendência internacional, acolhe com humanidade esse público, dispensando a ele, de forma ampla, direitos e garantias fundamentais, dentre os quais está o acesso à saúde.

Trata-se de uma garantia que, de acordo com os pontos suscitados no decorrer da pesquisa, vai muito além do bem-estar físico, devendo englobar também o bem-estar mental e social do indivíduo.

Dessa maneira, acolher o refugiado, garantindo a ele tratamento ambulatorial, vacinação, leito em hospitais, ainda continuam sendo providências de primeira necessidade, e que, dada a importância, devem continuar ocorrendo. Contudo, ao considerarmos a natureza holística da saúde, que envolve múltiplos fatores, a saúde deve ser considerada, também, em seu aspecto mental e social, de modo a ser garantida de forma integral a essa nova demanda populacional que chega em território nacional.

A vista disso, outras iniciativas como o Centro de Referência para a Saúde dos Refugiados, presente no Hospital de Servidores do Estado do Rio de Janeiro, assim como, o projeto intitulado "Fortalecimento de Capacidades Locais em Saúde Mental e Apoio Psicossocial no Contexto do Fluxo Migratório em Boa Vista, Roraima", que igualmente objetivam capacitar profissionais de saúde para dar apoio psicossocial aos refugiados, também devem ser implementadas em outras partes do país. Isso porque, apesar de realmente serem iniciativas excelentes, e que vão ao real encontro das necessidades desse contingente populacional tão vulnerável, não são capazes de atingir, por completo, a todos.

Isso implica dizer que, para bem atender a população de refugiados presentes em território nacional, cujas fragilidades envolvem questões físicas, mentais e sociais, muito ainda deve ser implementado, haja vista que se trata de um contingente populacional que cresce cada dia mais e que necessita e merece ser considerado em sua dignidade, enquanto seres humanos que são. 


\section{REFERÊNCIAS BIBLIOGRÁFICAS}

BORGES, Lucienne Martins; POCREAU, Jean-Bernard. Serviço de atendimento psicológico especializado aos imigrantes e refugiados: interface entre o social, a saúde e a clínica. Estudos de psicologia, v. 29, n. 4, p. 577-585, 2012.

BRASIL. Constituição da República Federativa do Brasil de 1988. Disponível em: < http://www.planalto.gov.br/ccivil_03/constituicao/constituicao.htm>. Acesso em: 09 jan. 2020.

Decreto $N^{\circ}$ 591, de 6 de julho de 1992. Atos Internacionais. Pacto Internacional sobre Direitos Econômicos, Sociais e Culturais. Promulgação. Disponível em: <http://www.planalto.gov.br/ccivil_03/decreto/1990-1994/d0591.htm>. Acesso em: 09 jan. 2020.

Decreto № 678, de 6 de novembro de 1992. Promulga a Convenção Americana sobre Direitos Humanos (Pacto de São José da Costa Rica), de 22 de novembro de 1969. Disponível em: < http://www.planalto.gov.br/ccivil_03/decreto/D0678.htm>. Acesso em: 09 jan. 2020.

Decreto $\mathrm{N}^{\circ} 50.215$, de 28 de janeiro de 1961. Promulga a Convenção relativa ao Estatuto dos Refugiados, concluída em Genebra, em 28 de julho de 1951. Disponível em: < http://www.planalto.gov.br/ccivil_03/decreto/1950-1969/D50215.htm>. Acesso em: 09 jan. 2020.

. Decreto No 70.946, de 7 de agosto de 1972. Promulga o Protocolo sobre o Estatuto dos Refugiados. Disponível em: <http://www.planalto.gov.br/ccivil_03/ decreto/19701979/D70946.htm>. Acesso em: 09 jan. 2020.

Lei $\mathbf{N}^{\circ} \mathbf{8 . 0 8 0}$, de 19 de setembro de 1990. Dispõe sobre as condições para a promoção, proteção e recuperação da saúde, a organização e o funcionamento dos serviços correspondentes e dá outras providências. Disponível em: <http://www.planalto.gov.br/ccivil_03/leis/L8080.htm>. Acesso em: 11 jan. 2020.

CARTILHA PARA REFUGIADOS NO BRASIL. Disponível em: <https://www.acnur.org/portugues/wp-content/uploads/2018/02/Cartilha-para-Refugiados-noBrasil_ACNUR-2014.pdf>. Acesso em: 12 jan. 2020. DICIO. Dicionário Online de Português. Disponível em: <https://www.dicio.com.br/ refugio/>. Acesso em: 08 jan. 2020.

MARTINS-BORGES, Lucienne. Migração involuntária como fator de risco à saúde mental. REMHU: Revista Interdisciplinar da Mobilidade Humana, v. 21, n. 40, p. 151-162, 2013.

MAZZUOLI, Valério de Oliveira. Curso de Direito Internacional Público. 11. ed. Rio de Janeiro: Forense, 2018.

MILES, Rosita. CARLET, Flavia. Refugiados e Políticas Públicas: pela solidariedade, contra a exploração. IMDH Instituto Migrações e Direitos Humanos. 2016. Disponível em: < https://www.migrante.org.br/refugiados-e-refugiadas/refugiados-e-politicas-publicas-pelasolidariedade-contra-a-exploracao/>. Acesso em: 18 jan. 2020.

MINISTÉRIO DA JUSTIÇA E SEGURANÇA PÚBLICA. Refúgio em Números e Publicações. Disponível em: <https://www.justica.gov.br/seus-direitos/refugio/refugio-em-numeros>. Acesso em: 12 jan. 2020.

NAÇÕES UNIDAS BRASIL. Oficinas em Boa Vista (RR) visam fortalecer atendimento psicossocial e de saúde mental. Disponível em: <https://nacoesunidas.org/oficinas-em-boavista-rr-visam-fortalecer-atendimento-psicossocial-e-de-saude-mental/>. Acesso em: 12 jan. 2020. 
OLIVEIRA, Ricardo Filipe Rodrigues de. Direito à Saúde dos Refugiados: Perspectivas do Direito Português. e-Pública: Revista Eletrónica de Direito Público, v. 3, n. 1, p. 207-229, 2016.

OPAS/OMS BRASIL. OPAS/OMS apoia governos no objetivo de fortalecer e promover a saúde mental da população. Disponível em: < https://www.paho.org/bra/index.php? option=com_content\&view=article\&id=5263:opas-oms-apoia-governos-no-objetivo-de-fortalecere-promover-a-saude-mental-da-populacao\&ltemid=839>. Acesso em: 11 jan. 2020.

ORGANIZAÇÃO DAS NAÇÕES UNIDAS. Declaração Universal dos Direitos Humanos. Disponível em: <http://www.un.org/en/universal-declaration-human-rights/index.html>. Acesso em 08 jan. 2020.

PINHEIRO, Carla. Manual de Psicologia Jurídica. 4. ed. São Paulo: Saraiva, 2017.

RAMOS, André de Carvalho. Teoria dos direitos humanos na ordem internacional. 6. ed. São Paulo: Saraiva, 2016.

UNHCR ACNUR AGÊNCIA DA ONU PARA REFUGIADOS. Dados sobre Refúgio. Disponível em: <https://www.acnur.org/portugues/dados-sobre-refugio/>. Acesso em 08 jan. 2020.

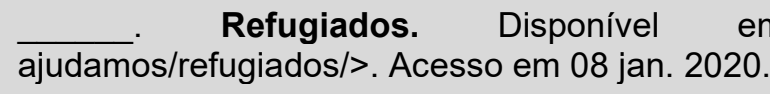

VALDES, Lysian Carolina. Refugiados e o acesso ao direito fundamental à saúde. interJuris, 3. ed. p. 61, 2016. 